\title{
半透明太阳能电池的热力学极限效率研究
}

\author{
吉永记，刘 东，李强 \\ (南京理工大学 能源与动力工程学院, 南京 210094)
}

摘 要: 半透明太阳能电池可充分利用现代建筑的太阳照射面积, 具有广阔的应用前景, 其热力学极限效率是重要 的基础问题。本工作将已有研究中用于建筑窗户的无色半透明太阳能电池拓展至可安装于建筑幕墙表面的彩色半 透明太阳能电池, 基于细致平衡原理计算其热力学极限效率, 以便更全面地描绘半透明太阳能电池在建筑一体化 应用的前景。结果表明, 用于窗户的无色半透明太阳能电池的极限效率为 $18.1 \%$, 而安装于蓝色建筑幕墙表面的半 透明太阳能电池的极限效率高达 $28.3 \%$, 提升了 10 个百分点。本研究的彩色半透明太阳能电池扩大了可利用的太 阳照射面积, 有望弥补太阳能能量密度低的问题。研究结果可以指导选择合适的半导体材料和设计新材料。

关 键 词: 半透明太阳能电池; 极限效率; 建筑光伏一体化; 选择性吸收材料

中图分类号: TK51 文献标志码: A

\section{Thermodynamic Efficiency Limits of Semitransparent Solar Cells}

\author{
JI Yongji, LIU Dong, LI Qiang \\ (School of Energy and Power Engineering, Nanjing University of Science and Technology, Nanjing 210094, China)
}

\begin{abstract}
Semitransparent photovoltaics (STPV) is a promising solar energy harvesting technology because it can be integrated to harness huge sun-facing areas of modern buildings for electricity generation. Its thermodynamic efficiency limits are of fundamental interest. This work extended the analyses from neutral STPV for building windows to those installed on the surface of colored building envelops according to the principle of detailed balance. Results show that the efficiency limit of STPV for blue building envelops is as high as $28.3 \%$, which represents a $10 \%$ absolute enhancement compared to the neutral STPV for building windows (18.1\%). These results demonstrate that STPV can be integrated into both windows and envelops of modern buildings, which has the potential to offset the low density of solar energy. This work provides guidelines on the selection and the development of active materials for STPV.
\end{abstract}

Key words: semitransparent solar cell; efficiency limit; building-integrated photovoltaic; selective-absorption material

太阳能的总量丰富，作为清洁、可再生能源 ${ }^{[1]}$, 其大规模利用对我国推进节能减排、优化能源结构
至关重要。但是太阳能的能量密度只有 $1000 \mathrm{~W} \cdot \mathrm{m}^{-2}$, 只有巨大的照射面积才能提供充足的电量, 最缺电

收稿日期：2021-03-16; 收到修改稿日期：2021-06-09; 网络出版日期：2020-06-30

基金项目: 国家自然科学基金(51976090，51888103); 江苏省自然科学基金(BK20200072); 中央高校基本科研业务费专项 资金(30919011403)

National Natural Science Foundation of China (51976090, 51888103); Natural Science Foundation of Jiangsu Province (BK20200072); Fundamental Research Funds for the Central Universities (30919011403)

作者简介：吉永记(1996-), 男, 硕士研究生. E-mail: 118108010866@njust.edu.cn JI Yongji(1996-), male, Master candidate. E-mail: 118108010866@njust.edu.cn

通信作者: 刘 东, 教授. E-mail: liudong15@njust.edu.cn; 李 强, 教授. E-mail: liqiang@njust.edu.cn LIU Dong, professor. E-mail: liudong15@njust.edu.cn; LI Qiang, professor. E-mail: liqiang@njust.edu.cn 
的地方恰恰是可利用占地面积极为有限的城市。现 代城市高层建筑林立, 半透明太阳能电池可充分利 用现代建筑的窗户, 显著增大太阳能发电利用面积, 已成为国际能源科学的前沿方 向 $^{[2]}$ 。

半透明太阳能电池在可见光波段具有一定的透 光性, 其光电转换效率(后文统一简称为效率)的热 力学极限与经典的 Shockley-Queisser 极限 ${ }^{[3-4]}$ 不同, 需要开发新的理论和研究方法计算半透明太阳能电 池的热力学极限效率。已有半透明太阳能电池的研 究主要侧重材料 ${ }^{[5]}$ 、电极 ${ }^{[6-8]}$ 和器件 ${ }^{[9-13]}$ 的实验研究, 针对极限效率的理论研究较少 ${ }^{[14-15]}$ 。一般认为, 半 透明太阳能电池只能用于建筑窗户 ${ }^{[16]}$, Lunt ${ }^{[15]}$ 只计 算了无色半透明太阳能电池的极限效率。现代建筑 的幕墙同样拥有巨大的太阳照射面积, 可用于安装 半透明太阳能电池, 既可以收集太阳能又不影响彩 色幕墙的原有功能。

鉴于此, 本研究聚焦可安装于建筑幕墙表面的 彩色半透明太阳能电池, 开发新的理论和方法计算 其热力学极限效率, 以便更全面地描绘半透明太阳 能电池在建筑一体化应用的前景。

\section{1 计算方法}

本研究只考虑单结太阳能电池, 并且其颜色和 光谱特性(光谱吸收率、光谱透过率) 只由半导体材 料的属性决定, 即太阳能电池与半导体材料两者的 光谱特性一致, 不考虑在太阳能电池表面或内部引 入光学涂层或光学结构调控太阳能电池的光谱特 性 $^{[17-18]}$, 因此, 本研究计算的极限效率相对保守。

另外, 半导体材料的吸收光谱, 也就是太阳能 电池的吸收光谱通常是连续的, 例如带隙 $2.1 \mathrm{eV}$ 的 半导体材料在波长短于 $600 \mathrm{~nm}$ 的所有光谱范围内 都表现出强吸收特性, 太阳能电池迎着阳光呈现红 色; 随着具有选择性吸收特性的新材料的开发 ${ }^{[19]}$, 太 阳能电池的吸收光谱可以不连续, 例如带隙 $2.1 \mathrm{eV}$ 的半导体材料可以选择性吸收 500 600 nm 的光子、 透过波长小于 $500 \mathrm{~nm}$ 的光子, 太阳能电池呈品红 色。无论是采用常规还是选择性吸收半导体材料, 太阳能电池吸收光谱在可见光至近红外波段只有一 个吸收平台。紫外波段只占全部太阳能的 $4 \%$, 且几 乎所有半导体材料在紫外波段都具有强吸收特性, 简单假设本研究考虑的所有太阳能电池在紫外波段 的吸收率为 $100 \%$ 。

本研究从细致平衡原理 ${ }^{[3-4]}$ 出发计算半透明太 阳能电池的极限效率, 简要描述如下。太阳能电池 的电流密度-电压曲线 $(J(V))$ 的一般表达式为式(1):

$$
J(V)=J_{\mathrm{ph}}-J_{\text {rec }}(V)
$$

即, 总电流密度由正向光生电流密度 $\left(J_{\mathrm{ph}}\right)$ 与负向复 合电流密度 $\left(J_{\mathrm{rec}}\right)$ 组成。

理想条件下, $J_{\mathrm{ph}}$ 与短路电流密度 $\left(J_{\mathrm{sc}}\right)$ 相等, 与 电压 $V$ 无关，表达式为式(2):

$$
J_{\mathrm{ph}}=J_{\mathrm{sc}}=q \int_{0}^{\lambda_{g}} \operatorname{EQE}(\lambda) \frac{S(\lambda)}{h c / \lambda} \mathrm{d} \lambda
$$

式中, EQE 为外部量子效率, $S$ 为 $\mathrm{AM} 1.5 \mathrm{G}$ 太阳光谱 ${ }^{[20]}$, $q$ 为元电荷, $h$ 为普朗克常数, $c$ 为真空中的光速, $\lambda$ 为波长, $\lambda_{\mathrm{g}}$ 为材料带隙 $\left(E_{\mathrm{g}}\right)$ 对应的波长。理想条件下, 外部量子效率表达式为式(3):

$$
\operatorname{EQE}(\lambda)= \begin{cases}A(\lambda)=1-T(\lambda), & 0<\lambda \leqslant \lambda_{g} \\ 0, & \lambda>\lambda_{g}\end{cases}
$$

式中, $A$ 和 $T$ 分别为光谱吸收率和透过率。

理想条件下, $J_{\mathrm{rec}}$ 仅包含辐射复合电流密度 $\left(J_{\mathrm{rad}}\right)$, 为电压 $V$ 的函数, 表达式为式(4) ${ }^{[21]}$.

$$
J_{\text {rec }}(V)=J_{\text {rad }}(V)=J_{0}\left[\exp \left(\frac{q V}{k T}\right)-1\right]
$$

式中, $k$ 为玻尔兹曼常数, $T=298.15 \mathrm{~K}, J_{0}$ 为暗态、无 偏压、平衡条件下的辐射复合电流密度, 表达式见 式(5):

$$
J_{0}=q \int_{0}^{\infty} A(E) \frac{2 \pi}{h^{3} c^{2}} \frac{E^{2}}{\exp \left(\frac{E}{k T}\right)-1} \mathrm{~d} E
$$

太阳能电池的效率 $\mathrm{PCE}=\left([J(V) V]_{\max } / P_{\text {in }}\right) \times 100 \%$, 其中, $P_{\mathrm{in}}=1000 \mathrm{~W} \cdot \mathrm{m}^{-2}$ 。最大功率点对应的电流和电 压分别为 $J_{\mathrm{mpp}} 、 V_{\mathrm{mpp}}$ 填充因子 $F F=\left(J_{\mathrm{mpp}} \cdot V_{\mathrm{mpp}}\right) /\left(J_{\mathrm{sc}} \cdot V_{\mathrm{oc}}\right)$ 。

\section{2 结果与讨论}

\section{1 无色半透明太阳能电池}

本研究首先考虑无色半透明太阳能电池并以其 为基准。理想情况下, 无色半透明太阳能电池选择 性吸收可见光以外的太阳能, 需要确定可见光波段 范围。本研究采用 Schuber ${ }^{[22]}$ 的定义, 可见光波段范 围定为 390 720 nm。可见光波段平均透过率(AVT) 是 评价半透明太阳能电池的重要指标, 定义为式(6) ${ }^{[22]}$.

$$
\operatorname{AVT}=\frac{\int_{380 \mathrm{~nm}}^{780 \mathrm{~mm}} T(\lambda) P(\lambda) S(\lambda) \mathrm{d} \lambda}{\int_{380 \mathrm{~nm}}^{780 \mathrm{~nm}} P(\lambda) S(\lambda) \mathrm{d} \lambda}
$$

式中, $T$ 为光谱透过率; $P$ 反映了人眼对可见光的响 应, $P$ 和 $S$ 如图 1 所示。波长 390 720 nm 范围内, $P>0.001, T=100 \%$ 对应 AVT 约 100\%(>99.99\%); 波 
长 380 390 nm 以及 720 780 nm 范围内, $T=0$, 因而 AVT 略小于 $100 \%$ 。 Lunt ${ }^{[15]}$ 依据显色指数(CRI) 将可 见光波段定为 $435 \sim 670 \mathrm{~nm}$, 在这个波长范围内 $T=$ $100 \%$ 对应 AVT 减小至 $99.5 \%$ 。可以看出, 依据人眼 响应和 AVT 定义的可见光波段范围，与 $T=100 \%$ 、 $\mathrm{AVT}=100 \%$ 的范围基本对应，这种定义更通俗、直观。

波长 390 720 nm 范围内, 若 $\mathrm{AVT}=0 、 A=100 \%$, 极限效率即为经典的 Shockley-Queisser(SQ)极限, 即理想黑色不透明太阳能电池的热力学极限效率。 如图 2 所示, $\mathrm{AVT}=0 、 A=100 \%$ 对应效率的计算结果 为 $33.7 \%$, 与 $\mathrm{SQ}$ 极限 $33.2 \%$ 吻合 ${ }^{[4]}$, 验证了本研究 中计算方法的可靠性。

无色半透明太阳能电池的极限效率随 AVT 的 变化示于图 3。随着 AVT 增大, 半透明太阳能电池 吸收的能量减少, 极限效率降低, 且近似线性变化。 $\mathrm{AVT}=100 \%$ 、即太阳能电池完全透明时，极限效率 高达 $18.1 \%$, 达到 SQ 极限的 54\%。本研究计算结果 与 Lunt ${ }^{[15]}$ 报道的效率 $21 \%$ 略有不同, 这是因为本研 究定义的可见光波段比 Lunt ${ }^{[15]}$ 更宽, 可吸收的近红 外波段能量更少。无色半透明太阳能电池的效率如

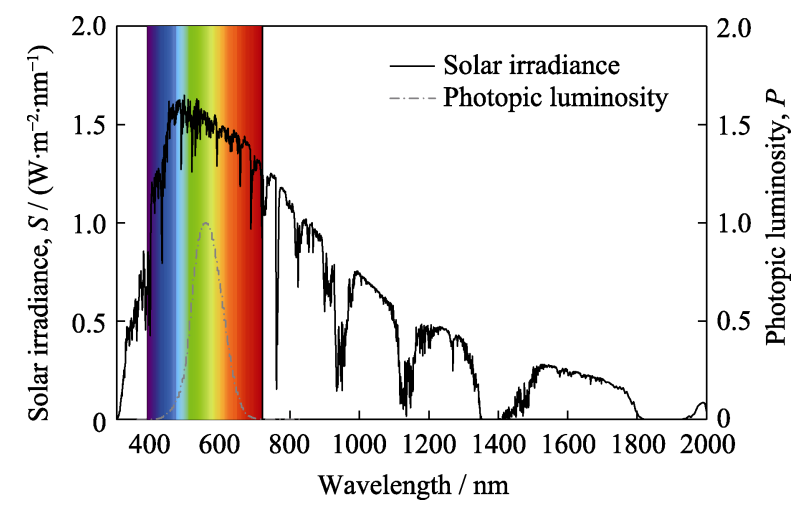

图 1 AM1.5G 太阳光谱与人眼对可见光的响应系数 ${ }^{[20,22]}$ Fig. 1 AM1.5G solar spectrum and photopic luminosity ${ }^{[20,22]}$

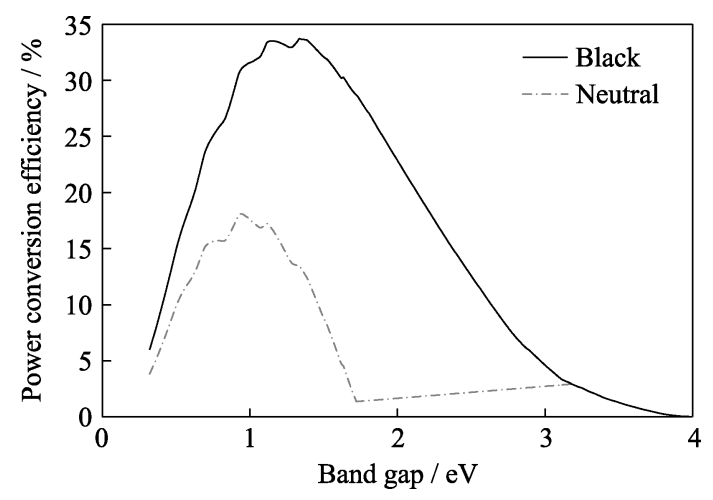

图 2 黑色不透明与无色完全透明太阳能电池的效率随半导 体材料带隙的变化

Fig. 2 Efficiencies of black opaque and neutral transparent solar cells varied with the semiconductor bandgap

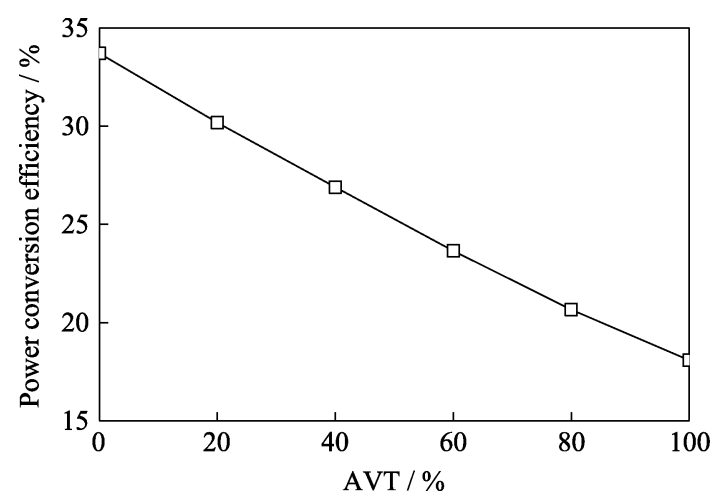

图 3 无色半透明太阳能电池的极限效率随 AVT 的变化

Fig. 3 Efficiency limits of neutral semitransparent solar cells varied with AVT

此可观, 是因为设定其可以完全吸收近红外波段太 阳能，而这部分能量占全部太阳能的 $50 \%$, 与 Lunt ${ }^{[15]}$ 的报道共同揭示了半透明太阳能电池应用于建筑窗 户的巨大前景。

无色半透明太阳能电池与黑色不透明太阳能电 池的另一个区别是半导体带隙在 $1.72 \sim 3.18 \mathrm{eV}$ 范围 内变化时, 无色半透明太阳能电池的效率随着带隙 增大而提高, 如图 2 所示。1.72 3.18 eV 对应的波长 范围是 390 720 nm, 与本研究定义的可见光波段范 围一致。无色半透明太阳能电池在可见光波段 $A=0$ 、 $\mathrm{AVT}=100 \%$, 半导体带隙在 $1.72 \sim 3.18 \mathrm{eV}$ 范围变化 时, 电池短路电流不变, 开路电压随带隙增大而增 大，效率随之提高。

\section{2 彩色半透明太阳能电池}

进一步考虑安装于彩色建筑幕墙表面的半透明 太阳能电池。以两类、五种颜色的典型幕墙为例。 第一类为加法基本颜色 (RGB), 包括蓝色和红色。半 透明太阳能电池安装于蓝色幕墙表面除了吸收近红 外光波段太阳能, 还可选择性吸收绿光和红光波段 太阳光; 对于红色幕墙, 半透明太阳能电池选择性 吸收蓝光和绿光波段太阳光。而绿色幕墙若与蓝色 和红色做相似处理, 太阳能电池需吸收蓝光和红光 波段太阳光, 存在两个吸收平台 ${ }^{[23]}$, 需引入光学涂 层或结构, 本研究不做考虑。可直接采用基准无色 半透明太阳能电池安装于绿色幕墙表面, 此时极限 效率与基准无色半透明太阳能电池相同, 不在结果 中展示。第二类为减法基本颜色 (CMY), 包括黄色、 品红色和青色, 对应的半透明太阳能电池分别选择 性吸收蓝光波段、绿光波段以及红光/近红外光波段 太阳光。

表 1 中 1)选择性吸收波段范围依据 Yang 等 ${ }^{[24]}$ 的文献确定；2)设定理想的半透明太阳能电池在选 择性吸收波段吸收率为 $100 \%$, 其它波段透过率为 
表 1 半透明太阳能电池的参数

Table 1 Parameters for semitransparent solar cells

\begin{tabular}{ccccccc}
\hline STPV & Absorption band & $\mathrm{PCE} / \%$ & $J_{\mathrm{sc}} /\left(\mathrm{mA} \cdot \mathrm{cm}^{-2}\right)$ & $V_{\mathrm{oc}} / \mathrm{V}$ & $\mathrm{FF} / \%$ & $E_{\mathrm{g}, \mathrm{op}} / \mathrm{eV}$ \\
\hline Neutral & $>720 \mathrm{~nm}$ & 18.1 & 30.64 & 0.70 & 84.4 & 0.94 \\
Blue & $>500 \mathrm{~nm}$ & 28.3 & 37.00 & 0.88 & 86.9 & 1.13 \\
Red & $<600 \mathrm{~nm}$ & 21.4 & 13.18 & 1.76 & 92.3 & 2.06 \\
Yellow & $<500 \mathrm{~nm}$ & 13.0 & 6.48 & 2.14 & 93.7 & 2.48 \\
Magenta & $500-600 \mathrm{~nm}$ & 10.9 & 6.76 & 1.74 & 92.7 & 2.06 \\
Cyan & $>600 \mathrm{~nm}$ & 23.1 & 30.79 & 0.87 & 86.2 & 1.12 \\
\hline
\end{tabular}

$100 \%$ ；3)对应五种颜色幕墙的半透明太阳能电池， 迎着太阳观察分别呈现蓝、红、黄、品红和青色, 因 而记为相应颜色的半透明太阳能电池。

彩色半透明太阳能电池极限效率的计算结果见 图 4 和图 5。蓝色、红色和青色半透明太阳能电池 的极限效率分别为 $28.3 \% 、 21.4 \%$ 和 $23.1 \%$, 高于无 色半透明太阳能电池; 蓝色半透明太阳能电池的极 限效率甚至达到了 SQ 极限的 $84 \%$ 。黄色和品红色

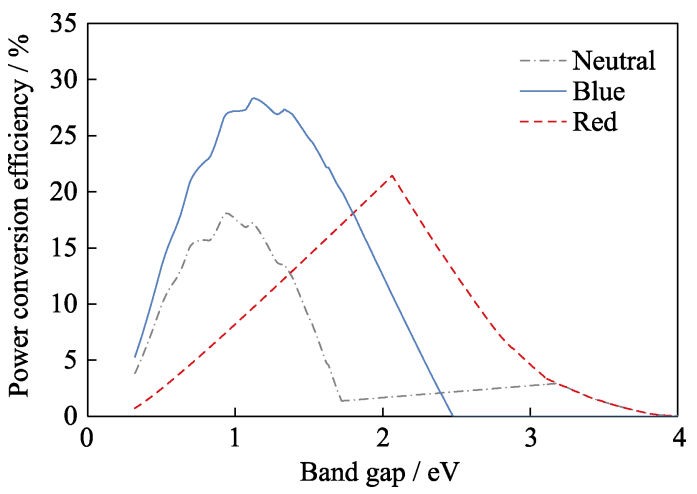

图 4 无色以及蓝色和红色(加法基本颜色)半透明太阳能电 池的效率随半导体材料带隙的变化

Fig. 4 Efficiencies of neutral as well as blue and red (additive colors) semitransparent solar cells varied with the semiconductor bandgap

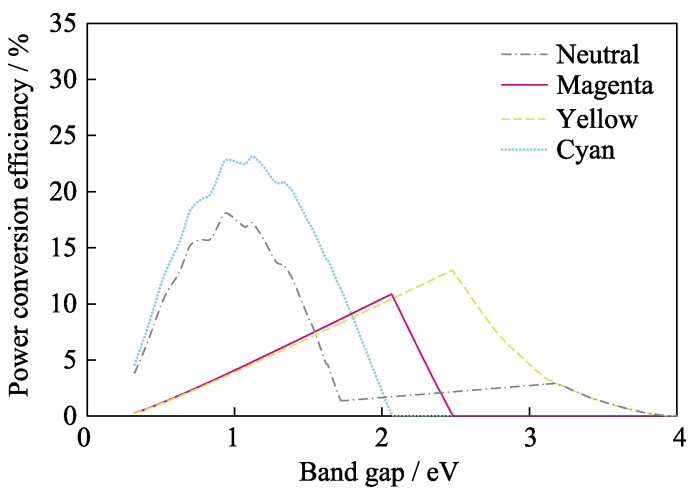

图 5 黄色、品红色和青色(减法基本颜色)半透明太阳能电 池的效率随半导体材料带隙的变化

Fig. 5 Efficiencies of yellow, magenta and cyan (subtractive colors) semitransparent solar cells varied with the semiconductor bandgap
半透明太阳能电池的极限效率为 $13.0 \%$ 和 $10.9 \%$, 低于无色半透明电池。前述计算方法表明，半透明 太阳能电池的选择性吸收光谱主要通过短路电流密 度影响效率。蓝色半透明太阳能电池吸收从绿光至 近红外光的宽波段太阳能, 短路电流密度达到 $37 \mathrm{~mA} \cdot \mathrm{cm}^{-2}$, 效率也最高。而品红色半透明太阳能 电池只吸收 500 600 nm 绿光窄波段太阳能, 短路 电流密度低于 $7 \mathrm{~mA} \cdot \mathrm{cm}^{-2}$, 效率最低。

\section{3 讨论}

前述极限效率的计算结果展示了半透明太阳能 电池在建筑幕墙表面的巨大应用前景。对于蓝色、 红色和青色建筑幕墙，应选择对应颜色的半透明太 阳能电池, 而绿色、黄色和品红色幕墙应选择无色 半透明太阳能电池, 如图 6 所示。

本研究结果对于选择半导体材料和设计新材料 有指导作用。无色、蓝色和青色半透明太阳能电池 的吸收光谱不连续( 见表 1), 高性能电池应采用具 有选择性吸收特性的有机半导体材料。以蓝色半透 明太阳能电池为例, 在 Traverse 等 ${ }^{[2]}$ 综述的数据库 中, 最优的有机半透明太阳能电池 ${ }^{[7]}$ 采用具有长波 选择性吸收的 BT-CIC 材料, 效率约 7\%, AVT 约 $40 \%$; 而蓝色无机非晶硅半透明太阳能电池 ${ }^{[10]}$ 在效 率同为 7\%的条件下, AVT 低于 15\%，如表 2 所示。 红色半透明太阳能电池的吸收光谱连续, 可采用光 电性能更好的无机半导体或钙钛矿材料。例如,

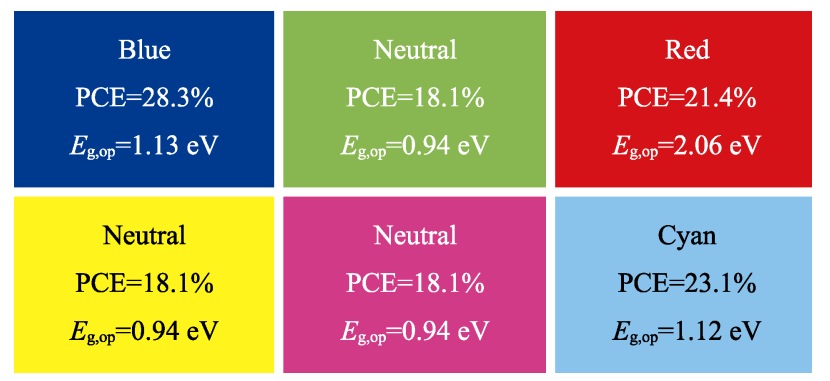

图 6 安装于不同颜色建筑幕墙表面的半透明太阳能电池及 对应的效率与最优带隙

Fig. 6 Semitransparent solar cells, their corresponding PCE and $E_{\mathrm{g}, \mathrm{op}}$ for colored building envelops 
表 2 典型彩色半透明太阳能电池的材料与性能 Table 2 Materials and performance of typical colored STPV

\begin{tabular}{ccccc}
\hline Color & Material & PCE $/ \%$ & AVT $/ \%$ & Ref. \\
\hline Blue & BT-CIC & 7.1 & 43.0 & [7] \\
Blue & a-Si & 7.2 & 14.2 & {$[10]$} \\
Red & $\mathrm{CH}_{3} \mathrm{NH}_{3} \mathrm{PbI}_{3-x} \mathrm{Cl}_{x}$ & 7.5 & 41.7 & {$[11]$} \\
\hline
\end{tabular}

Kwon 等 ${ }^{[11]}$ 报道的红色半透明太阳能电池, 与蓝色 半透明太阳能电池相比, 在 AVT 同为 $40 \%$ 的条件 下, 虽然极限效率低于蓝色半透明太阳能电池, 但 实际效率达到 7\%, 与蓝色半透明太阳能电池相当, 如表 2 所示。另一方面, 表 1 和图 6 的最优带隙 $\left(E_{\mathrm{g}, \mathrm{op}}\right)$ 也有助于选择太阳能电池半导体材料和设计新材料。

\section{3 结论}

1)已有研究低估了半透明太阳能电池在建筑一 体化中的应用前景。半透明太阳能电池除了用于建 筑窗户, 还可安装于彩色建筑幕墙表面; 相应地, 与无色半透明太阳能电池相比, 彩色半透明太阳能 电池的热力学极限效率最高可从 $18.1 \%$ 提升到 $28.3 \%$, 提升了 10 个百分点。

2)以加法和减法基本颜色为例, 对于蓝色、红 色和青色建筑幕墙, 应选择对应颜色的半透明太阳 能电池, 而绿色、黄色和品红色幕墙应选择无色半 透明太阳能电池。

3)无色、蓝色和青色半透明太阳能电池可以采 用具有选择吸收特性的有机半导体材料; 红色半透 明太阳能电池可以采用光电性能更好的无机半导体 或钙钛矿材料。最优带隙计算结果有助于选择合适 的半导体材料和设计新材料。

4)根据不同颜色对应的吸收光谱, 本研究方法 可推广至任意颜色。

\section{参考文献:}

[1] LEWIS N S. Research opportunities to advance solar energy utilization. Science, 2016, 351: aad1920.

[2] TRAVERSE C J, PANDEY R, BARR M C, et al. Emergence of highly transparent photovoltaics for distributed applications. Nature Energy, 2017, 2: 849-860.

[3] SHOCKLEY W, QUEISSER H J. Detailed balance limit of efficiency of P-N junction solar cells. Journal of Applied Physics, 1961, 32(3): 510-519.

[4] RUHLE S. Tabulated values of the Shockley-Queisser limit for single junction solar cells. Solar Energy, 2016, 130: 139-147.
[5] ALMORA O, BARAN D, BAZAN G C, et al. Device performance of emerging photovoltaic materials (version 1). Advanced Energy Materials, 2021, 11(11): 2002774.

[6] JI C, LIU D, ZHANG C, et al. Ultrathin-metal-film-based transparent electrodes with relative transmittance surpassing $100 \%$. Nature Communications, 2020, 11: 3367.

[7] WANG X, WANG R R, SHI L J, et al. Synthesis, optimization of $\mathrm{Cu}$ nanowires and application of its transparent electrodes. Journal of Inorganic Materials, 2019, 34(1): 49-59.

[8] LI XIN, XI L L, YANG J. First principles high-throughput research on thermoelectric materials: a review. Journal of Inorganic Materials, 2019, 34(3): 236-246.

[9] LI Y, LIN J, CHE X, et al. High efficiency near-infrared and semitransparent non-fullerene acceptor organic photovoltaic cells. Journal of the American Chemical Society, 2017, 139(47): 17114-17119.

[10] LI Y, JI C, QU Y, et al. Enhanced light utilization in semitransparent organic photovoltaics using an optical outcoupling architecture. Advanced Materials, 2019, 31(40): 1903173.

[11] LI Y, GUO X, PENG Z, et al. Color-neutral, semitransparent organic photovoltaics for power window applications. Proceedings of the National Academy of Sciences of the United States of America, 2020, 117(35): 21147-21154.

[12] MYONG S Y, JEON S W. Design of esthetic color for thin-film silicon semi-transparent photovoltaic modules. Solar Energy Materials \& Solar Cells, 2015, 143: 442-449.

[13] KWON H C, KIM A, LEE H, et al. Parallelized nanopillar perovskites for semitransparent solar cells using an anodized aluminum oxide scaffold. Advanced Energy Materials, 2016, 6: 1601055.

[14] WHEELER L M, WHEELER V M. Detailed balance analysis of photovoltaic windows. ACS Energy Letters, 2019, 4: 2130-2136.

[15] LUNT R R. Theoretical limits for visibly transparent photovoltaics. Applied Physics Letters, 2012, 101: 043902.

[16] HALME J, MAKINEN P. Theoretical efficiency limits of ideal coloured opaque photovoltaics. Energy \& Environmental Science, 2019, 12: 1274-1285.

[17] LIU D, WANG L, CUI Q, et al. Planar metasurfaces enable high-efficiency colored perovskite solar cells. Advanced Science, 2018, 5: 1800836.

[18] DENG K, LI L. Optical design in perovskite solar cells. Small Methods, 2020, 4(6): 1900150.

[19] CHANG S, CHENG P, LI G, et al. Transparent polymer photovoltaics for solar energy harvesting and beyond. Joule, 2018, 2: 1039-1054.

[20] Air Mass 1.5 Spectra, American Society for Testing and Materials. [2021-05-01] http://rredc.nrel.gov/solar/spectra/am1.5/.

[21] RAU U. Reciprocity relation between photovoltaic quantum efficiency and electroluminescent emission of solar cells. Physical Review B, 2007, 76(8): 085303.

[22] SCHUBER E F. Light-Emitting Diodes. New York: Cambridge University Press, 2006: 283.

[23] YANG Z, JI C, CUI Q, et al. High-purity hybrid structural colors by enhancing optical absorption of organic dyes in resonant cavity. Advanced Optical Materials, 2020, 8(12): 2000317.

[24] YANG Z, JI C, LIU D, et al. Enhancing the purity of reflective structural colors with ultrathin bilayer media as effective ideal absorbers. Advanced Optical Materials, 2019, 7(21): 1900739. 